\title{
RESTRAINED CONCRETE SHRINKAGE IN CASE OF STRENGTHENED BRIDGE PIERS BY CONCRETE JACKETING
}

\author{
Andreas P. Lampropoulos ${ }^{1}$, Ourania T. Tsioulou ${ }^{2}$, and Stephanos E. Dritsos ${ }^{2}$ \\ ${ }^{1}$ School of Environment and Technology, University of Brighton \\ Lewes Road, Brighton, BN2 4GJ, UK \\ a.lampropoulos@brighton.ac.uk \\ ${ }^{2}$ Department of Civil Engineering, University of Patras \\ Patras 26500, Greece \\ tsioulou@ upatras.gr, dritsos@upatras.gr
}

Keywords: bridge piers, concrete jackets, finite elements, restrained shrinkage.

Abstract. Reinforced concrete $(R C)$ jacketing of weak bridge pier columns is an effective retrofitting technique, particularly in seismic regions. The effect of restrained concrete shrinkage on the strength of concrete jackets is investigated in this study. A series of compressive tests are performed on square prism concrete specimens where steel plates are placed to represent the restrained shrinkage effect on the concrete of the jacket. Then, a numerical procedure to simulate the concrete shrinkage effect using the finite element method is proposed and results are justified and validated using the experimental data. The results indicate that restrained concrete shrinkage considerably reduces the stiffness and the maximum load of the strengthened elements. 


\section{INTRODUCTION}

Reinforced concrete (RC) jacketing of weak bridge pier columns is an effective retrofitting technique, particularly in seismic regions. Much experimental work has been performed in the area of strengthening existing structures using additional reinforced concrete layers and jackets [1-7] and it has been proved that a critical parameter for the performance of strengthened elements is the connection procedure between the jacket and the original column. An additional critical parameter for the response of the strengthened elements is the restrained concrete shrinkage. Experimental work has been conducted and it has been found that the compressive strength of concrete elements under restrained shrinkage can be considerably reduced due to a biaxial stress state [8].

In the present paper the findings of this experimental work have been used and finite element analyses have been conducted in monolithic and strengthened reinforced concrete columns with and without concrete shrinkage. The reliability of the numerical model has been examined in a previous study and it was found that the numerical model can accurately predict the response of strengthened elements when the interface between the old and the new concrete is simulated using two-dimensional contact elements and when concrete shrinkage is simulated using a volumetric strain [9]. The results of this study indicate that when jacket's shrinkage is simulated, strength and stiffness are reduced while the deflection at yield and failure is increased.

\section{EXPERIMENTAL INVESTIGATION}

The experimental investigation of the effect of restrained concrete shrinkage will be presented in this section. Fourteen identical specimens were examined. Seven were cast with steel plates $\left(A_{r}, B_{r}, C_{r}, D_{u}, E_{r}, F_{r}, G_{u}\right)$ representing the restraint shrinkage condition, and seven were cast with pieces of expanded polystyrene $\left(A_{f}, B_{f}, C_{f}, D_{f}, E_{f}, F_{f}, G_{f}\right)$ representing the free shrinkage condition [8]. Specimens' geometry is presented in figure 1.
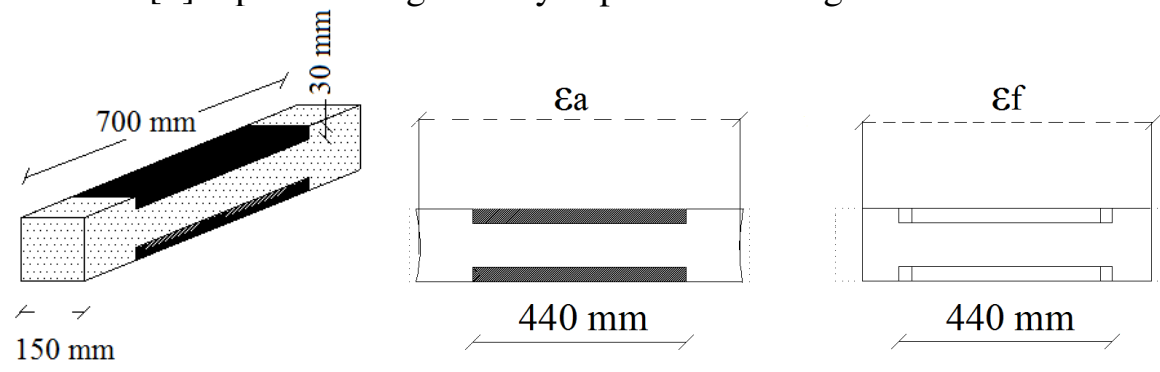

Figure 1: Specimens' geometry.

These specimens were stored until testing in a room with a constant temperature of $25{ }^{\circ} \mathrm{C}$ and a relative humidity of $50 \%$. Dial gauges were placed at the ends of the specimens to measure concrete shrinkage strain (figure 2a) [8]. Then the specimens were tested under compression (figure $2 \mathrm{~b}$ ). The specimens with the steel plates were tested first and then the steel plates were removed from the broken specimen and used to replace the expanded polystyrene in the other specimens before testing. For two pairs of specimens, D and G, the steel plates were removed from the specimens in order to unload the tensile stresses due to restrained shrinkage. Then the steel plates were reattached to the specimens to perform the compressive tests [8]. 


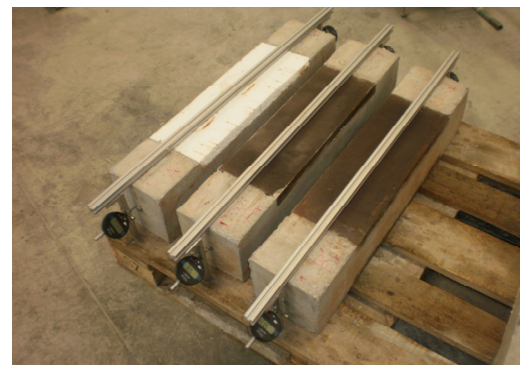

(a)

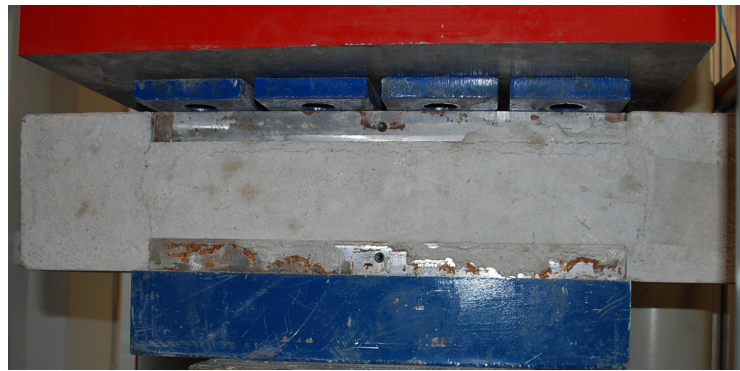

(b)

Figure 2: Experimental setup a) for the measurement of shrinkage strain and b) for the compressive testing.

The maximum load for each specimen and the strength reduction due to restrained concrete shrinkage are presented in table 1.

\begin{tabular}{|c|c|c|c|c|}
\hline \multicolumn{2}{|c|}{ Specimens } & Description & $\begin{array}{l}\text { Maximum } \\
\text { load }(\mathrm{kN})\end{array}$ & $\begin{array}{c}\text { Strength } \\
\text { reduction }(\%)\end{array}$ \\
\hline A & $A_{f}$ & Free concrete shrinkage & 1577.6 & \multirow{2}{*}{20} \\
\hline (14 days) & $A_{r}$ & Restrained concrete shrinkage & 1261.9 & \\
\hline & $\mathrm{B}_{\mathrm{f}}$ & Free concrete shrinkage & 1976.5 & \multirow{2}{*}{26} \\
\hline (28 days) & $\mathrm{B}_{\mathrm{r}}$ & Restrained concrete shrinkage & 1471.9 & \\
\hline $\mathrm{C}$ & $\mathrm{C}_{\mathrm{f}}$ & Free concrete shrinkage & 2092.2 & \multirow{2}{*}{24} \\
\hline (112 days) & $\mathrm{C}_{\mathrm{r}}$ & Restrained concrete shrinkage & 1579.9 & \\
\hline \multirow{2}{*}{$\begin{array}{c}\mathrm{D} \\
\text { (112 days) }\end{array}$} & $\mathrm{D}_{\mathrm{f}}$ & Free concrete shrinkage & 2399.5 & \multirow[b]{2}{*}{6} \\
\hline & $\mathrm{D}_{\mathrm{u}}$ & $\begin{array}{c}\text { Restrained concrete shrinkage and } \\
\text { unloading }\end{array}$ & 2244.3 & \\
\hline $\mathrm{E}$ & $\mathrm{E}_{\mathrm{f}}$ & Free concrete shrinkage & 2132.3 & \multirow{2}{*}{21} \\
\hline (14 days) & $\mathrm{E}_{\mathrm{r}}$ & Restrained concrete shrinkage & 1688.9 & \\
\hline $\mathrm{F}$ & $\mathrm{F}_{\mathrm{f}}$ & Free concrete shrinkage & 2444.8 & \multirow{2}{*}{28} \\
\hline (28 days) & $\mathrm{F}_{\mathrm{r}}$ & Restrained concrete shrinkage & 1770 & \\
\hline \multirow{2}{*}{$\begin{array}{c}\mathrm{G} \\
\text { (28 days) }\end{array}$} & $\mathrm{G}_{\mathrm{f}}$ & Free concrete shrinkage & 2444.8 & \\
\hline & $\mathrm{G}_{\mathrm{u}}$ & $\begin{array}{c}\text { Restrained concrete shrinkage and } \\
\text { unloading }\end{array}$ & 2308.7 & 6 \\
\hline
\end{tabular}

Table 1: Experimental results of maximum load and strength reduction due to restrained concrete shrinkage.

Equation 1 was used for the calculation of the tensile stress values perpendicular to the direction of the compressive loading.

$$
\sigma=E_{c t} \cdot \varepsilon_{r, e l}
$$

where:

$E_{c t}$ is the reduced modulus of elasticity taking into account the stress relief due to creep.

The following equations were used to calculate $E_{c t}[10]$ :

$$
E_{c t}=\frac{E_{c}}{1+x * C_{t}}, E_{c}=9500\left(f_{c m}\right)^{1 / 3}
$$

where:

$E_{c}$ is the modulus of elasticity of concrete. This was calculated using compressive test results of standard $150 \mathrm{~mm}$ concrete cubes;

$x$ is a coefficient that depends on the concrete age and can be considered to equal 0.8 ; 


$$
C_{t}=2.35 *\left(\frac{t^{0.6}}{10+t^{0.6}}\right) ;
$$

$t$ is the age in days; and

$f_{c m}$ is the concrete compressive strength.

The difference between the free $\left(\varepsilon_{f}\right)$ and the actual shrinkage $\left(\varepsilon_{\alpha}\right)$ of the specimens with restrained concrete shrinkage defines the restrained shrinkage strain $\left(\varepsilon_{r}\right)$. This strain comprises of the elastic $\left(\varepsilon_{r, e l}\right)$ and the plastic restrained shrinkage strain $\left(\varepsilon_{r, p l}\right)$. The elastic strain $\left(\varepsilon_{r, e l}\right)$ was used for the calculation of the tensile stresses (equation 1). To estimate $\varepsilon_{r, e l}$, the strain was measured when unloading the tensile stresses by removing the steel plates.

The tensile stress $(\sigma)$, the ratio of the tensile stress over the tensile strength $\left(\sigma / f_{t}\right)$, and the respective strength reduction $\left(\mathrm{f}_{\mathrm{c}, \text { shrink }} / \mathrm{f}_{\mathrm{c}, \text { free }}\right)$ are presented in table 2 .

\begin{tabular}{ccccccc}
\hline Specimen & $\mathrm{E}(\mathrm{MPa})$ & $\mathrm{E}_{\mathrm{ct}}(\mathrm{MPa})$ & $\begin{array}{c}\varepsilon_{\mathrm{r}, \mathrm{el}} \\
\text { (microstrains) }\end{array}$ & $\sigma(\mathrm{MPa})$ & $\sigma / \mathrm{f}_{\mathrm{t}}$ & $\mathrm{f}_{\mathrm{c}, \text { shrink }} / \mathrm{f}_{\mathrm{c}, \text { rree }}$ \\
\hline $\mathrm{A}$ & 22500 & 13925 & 46 & 0.64 & 0.38 & 0.80 \\
$\mathrm{~B}$ & 24200 & 13455 & 58 & 0.78 & 0.41 & 0.74 \\
$\mathrm{C}$ & 24200 & 11086 & 58 & 0.64 & 0.33 & 0.76 \\
$\mathrm{E}$ & 25800 & 15967 & 46 & 0.73 & 0.33 & 0.79 \\
$\mathrm{~F}$ & 26600 & 14790 & 58 & 0.86 & 0.37 & 0.72 \\
\hline
\end{tabular}

Table 2: Tensile stresses due to restrained concrete shrinkage and the respective strength reduction.

The compressive concrete strength reduction with the tensile stress due to restrained concrete shrinkage is presented in figure 3 together with the model proposed by Kupfer et al. [11] for concrete under biaxial stress state.

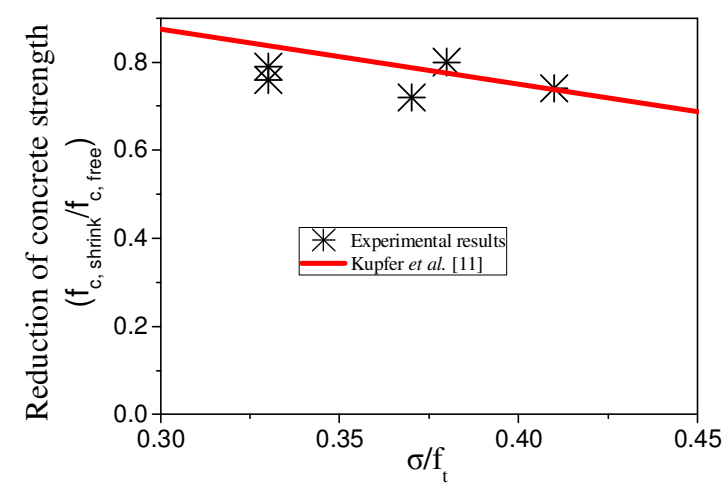

Figure 3: Concrete compressive strength reduction with the perpendicular tensile stress values.

From figure 3 , it can be observed that the experimental results are in a very good agreement with the model proposed by Kupfer et al. [11] for biaxial stress state. This model was adopted for the numerical simulation of this study. 


\section{NUMERICAL SIMULATION}

\subsection{Numerical Assumptions}

ATENA software [12] was used for the numerical simulation. To simulate the concrete, an eight-node element was used with nonlinear stress versus strain behaviour in compression and softening branches in both compression and tension. To simulate the steel, linear elements were used with a bilinear stress versus strain behaviour including strain hardening. These elements are capable of including the relative slip of the reinforcement in relation to the surrounding concrete.

The interface between the old and the new column was simulated using special contact elements with coefficients of friction and cohesion of 1.0 and $0.0 \mathrm{MPa}$, respectively. These values were used to model a well roughened interface as it has been demonstrated [9] that using low and constant values, strength degradation at the interface due to earthquake cyclic loading can be effectively simulated $[9,13]$.

The geometry and the material properties of the examined specimens were based on a previous work where the reliability of the numerical model was examined [9]. The cross sectional dimensions of the original columns were $250 \mathrm{~mm}$ by $250 \mathrm{~mm}$ and their height was 1800 $\mathrm{mm}$, while jacket thickness was $75 \mathrm{~mm}$ and placed to a height of $1300 \mathrm{~mm}$. The longitudinal reinforcement of the initial columns was 4 bars of $14 \mathrm{~mm}$ diameter with a yield stress of 313 $\mathrm{MPa}$ and a rupture stress of $442 \mathrm{MPa}$. Stirrups were $8 \mathrm{~mm}$ diameter spaced at every $200 \mathrm{~mm}$ with a yield stress of $425 \mathrm{MPa}$ and a rupture stress of $596 \mathrm{MPa}$. The longitudinal reinforcement of the jacket was 4 bars of $20 \mathrm{~mm}$ diameter with a yield stress of $487 \mathrm{MPa}$ and a rupture stress of $657 \mathrm{MPa}$. Jacket stirrups were $10 \mathrm{~mm}$ diameter spaced at every $100 \mathrm{~mm}$ with a yield stress of $599 \mathrm{MPa}$ and a rupture stress of $677 \mathrm{MPa}$. The concrete cover of the longitudinal reinforcement of the original column was $15 \mathrm{~mm}$. For the jacket, the cover was $25 \mathrm{~mm}$ when a 75 or $150 \mathrm{~mm}$ thick jacket was examined and it was $10 \mathrm{~mm}$ when a $25 \mathrm{~mm}$ thick jacket was considered. The concrete strengths of the initial columns and jackets were $27.0 \mathrm{MPa}$ and 55.8 $\mathrm{MPa}$, respectively. An axial load was applied to the top of the specimens and a horizontal displacement was applied to the columns at a height of $1600 \mathrm{~mm}$ above the footing [13]. The cross section of the examined model and the finite element model are presented in cross section of the examined columns are presented in figure 4.
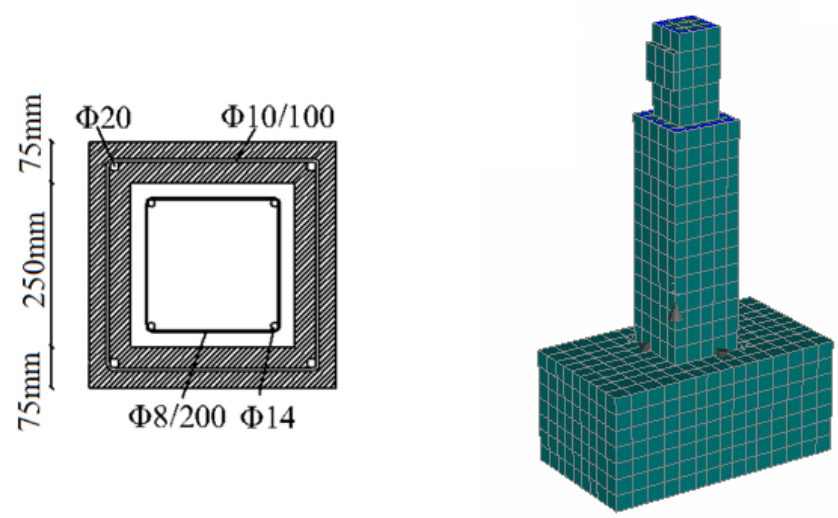

Figure 4: Cross section of the strengthened column and finite element model. 
Concrete shrinkage was simulated with a volumetric strain to the concrete elements of the jacket. In the present study, an ultimate free concrete shrinkage value of 800 microstrains was used. This value was considered to be reduced to half (400 microstrains) in order to include the stress relaxation due to creep $[13,14]$. The stress distribution in the column and the jacket is presented in the following figure (figure 5).

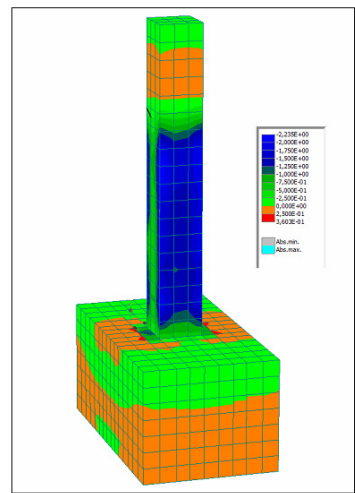

Compressive stress distribution in the initial column

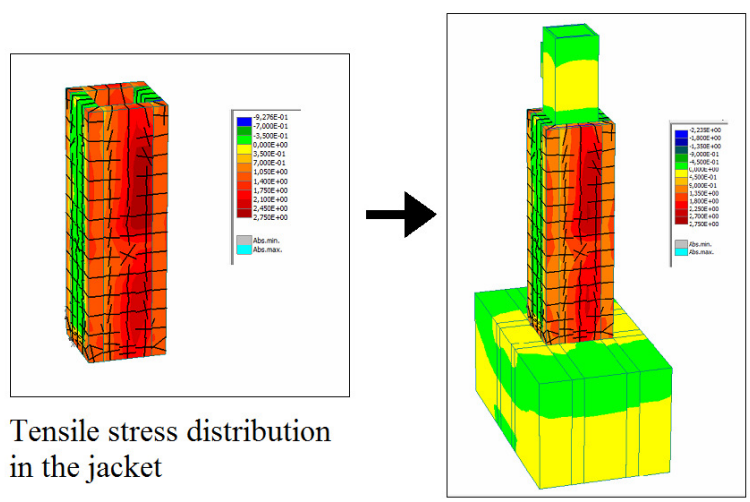

in the jacket

Figure 5: Stress distribution in the column and the jacket due to concrete shrinkage.

In figure 5, the tensile stresses of concrete jacket and the equivalent compressive stress distribution to the concrete of the initial column are presented. It can be observed that the tensile stress of the jacket exceeds the tensile strength and the concrete cracks due to restrained concrete shrinkage.

The results of the analyses of the strengthened columns with and without concrete shrinkage are compared to the experimental results. The numerical results of the respective monolithic specimen, where perfect bond between the old and the new concrete was assumed, are also presented (figure 6) [9].

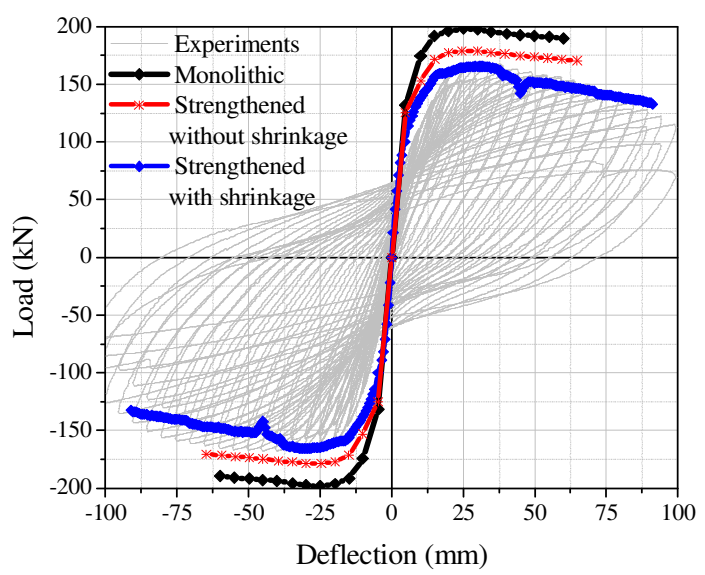

Figure 6: Load-deflection results of the analyses with and without concrete shrinkage together with available experimental results [9]. 
The simulation of concrete shrinkage considerably improved the accuracy of the numerical predictions. The analysis of the monolithic specimens overestimated the strength and the stiffness of the columns. The deviation between the numerical and the experimental results was reduced when the interface between the old and the new concrete was simulated ('Strengthened without shrinkage'). The results were found to be in a very good agreement with the experimental results when concrete shrinkage was also simulated.

\subsection{Parametric Study}

A parametric study was conducted in order to investigate the effect of the normalized axial load on the response of strengthened piers with RC jackets.

For the calculation of normalized axial load (v) values, equation 3 was used.

$$
v=\frac{N}{A_{c o} \cdot f_{c o}+A_{c j} \cdot f_{c j}},
$$

where:

$N$ is the applied axial load value;

$A_{c o}$ is the cross sectional area of the original column;

$f_{c o}$ is the concrete strength of the original column;

$A_{c j}$ is the cross sectional area of the concrete jacket; and

$f_{c j}$ is the concrete strength of the jacket.

Analyses were performed with and without concrete shrinkage for strengthened piers where the interface between the old and the new concrete was simulated. Respective monolithic specimens were also examined where perfect bond between the old and the new concrete was assumed. The results of the analyses with and without the simulation of concrete jacket's shrinkage are presented in figures $7 \mathrm{a}$ and $7 \mathrm{~b}$.

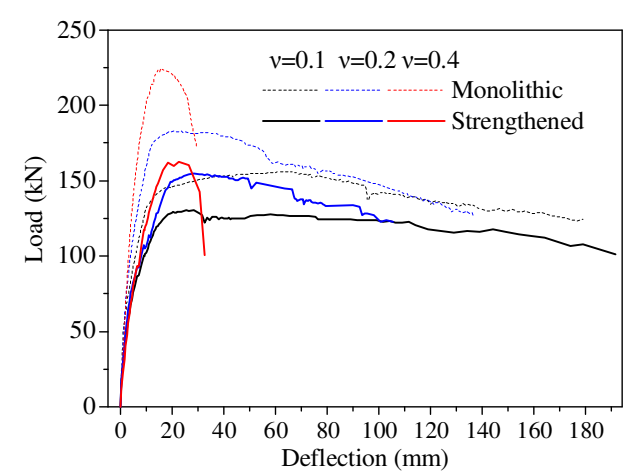

(a)

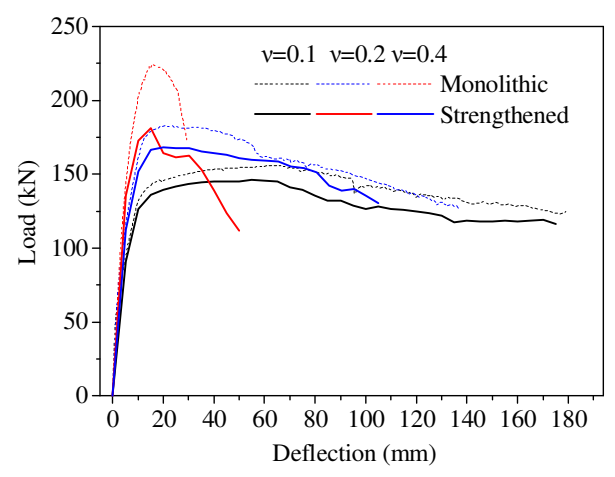

(b)

Figure 7: Load-deflection results of the analyses a) with and b) without concrete shrinkage for different values of normalized axial load values.

Monolithic coefficients for the strength, stiffness, and deflection $(\delta)$ or rotation angle $(\theta)$ at yield and failure were calculated using equation 4 . These coefficients correlate the behaviour of the strengthened specimens with the respective monolithic. 


$$
K_{F}=\frac{\left[F_{\max }\right]_{S T R}}{\left[F_{\max }\right]_{M O N}}, \quad K_{k}=\frac{\left[F_{y} / \delta_{Y}\right]_{S T R}}{\left[F_{y} / \delta_{Y}\right]_{M O N}}, \quad K_{\delta, \theta_{y}}=\frac{\left[\delta_{y}\right]_{S T R}}{\left[\delta_{y}\right]_{M O N}}, \quad K_{\delta, \theta_{u}}=\frac{\left[\delta_{u}\right]_{S T R}}{\left[\delta_{u}\right]_{M O N}},
$$

where:

$K_{F}, K_{k}$, and $K_{\delta, \theta_{y, u}}$ are monolithic coefficients for the strength, stiffness, and deflection or rotation angle, respectively;

$F_{y}$ and $F_{\max }$ are the yield and maximum load; and

$\delta_{y}$ and $\delta_{u}$ are the deflections at yield and failure.

Subscripts $S T R$ and $M O N$ indicate strengthened and monolithic specimens, respectively [13].

To estimate the load and the deflection at yield point, the load versus deflection curve up to the maximum load was converted to an equivalent bilinear approximation according to the procedure proposed in ATC 40 [15]. Failure was considered to occur when the load capacity was reduced to $80 \%$ of the maximum load value. Using this procedure, the load versus deflection curve was converted to an equivalent tri-linear distribution based on the characteristic points of yield, maximum load and failure of the specimen. These equivalent points were then used to calculate monolithic coefficient values (equation 4) [13].

The tri-linear load deflection curves of monolithic and strengthened columns with and without concrete shrinkage have been calculated and the results are presented in figure 8 .

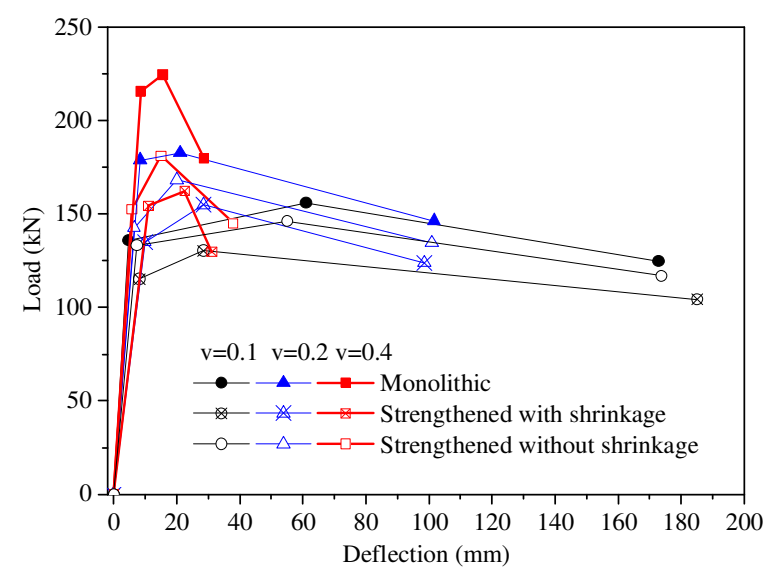

Figure 8: Tri-linear load-deflection results of the analyses with and without the simulation of concrete shrinkage.

Using the results of figure 8 and equation 4 , the monolithic coefficient values for strength, stiffness, and deflection or rotation angle at yield and failure were calculated. Figure 9 shows the distribution of these values with the normalized axial load. 


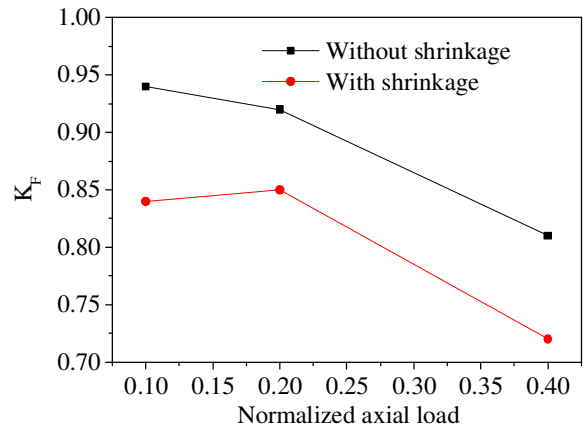

(a)

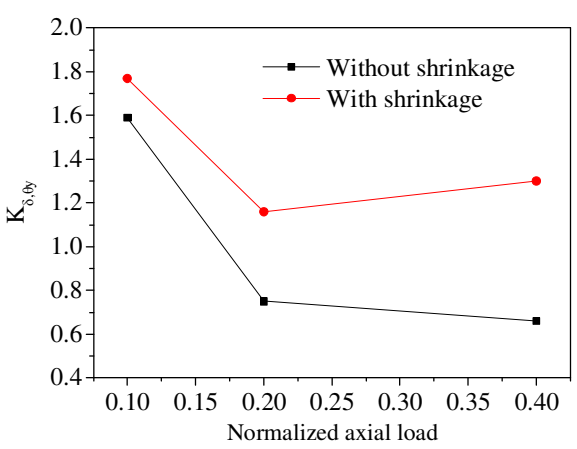

(c)

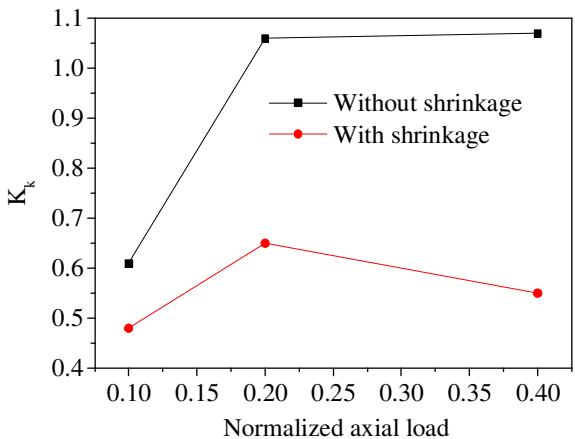

(b)

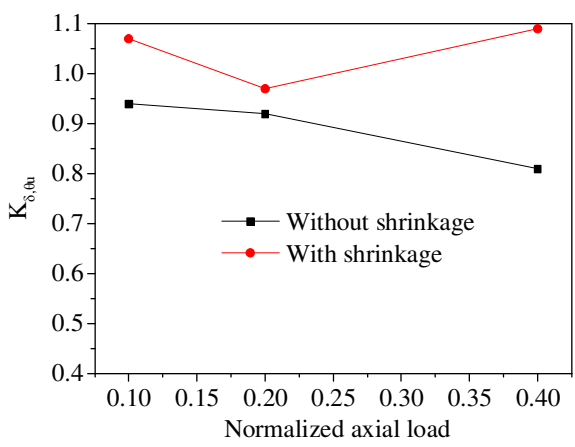

(d)

Figure 9: Monolithic coefficient value distribution with the normalized axial load values for the a) strength, b) stiffness, and c,d) deflection/ rotation angle at yield and at failure.

From the results of figure 9 , it can be observed that the strength and the stiffness are reduced when concrete shrinkage is simulated, while the deflection/rotation angle at yield and failure is increased. The effect of concrete shrinkage is summarized in table 3.

\begin{tabular}{cccccc}
\hline & & \multicolumn{4}{c}{ Shrinkage effect } \\
& $v$ & $\begin{array}{c}\text { Strength } \\
\text { reduction } \\
\end{array}$ & & $\begin{array}{c}\text { Stiffness } \\
\text { reduction }\end{array}$ & $\begin{array}{c}\text { Deflection/ } \\
\text { rotation angle increment (\%) }\end{array}$ \\
\cline { 5 - 7 } & & $1 \%)$ & at yield & at failure \\
\hline Numerical investi- & 0.1 & 11 & 21 & 11 & 14 \\
gation & 0.2 & 8 & 39 & 55 & 5 \\
& 0.4 & 11 & 49 & 97 & 35 \\
\hline
\end{tabular}

Table 3: Shrinkage effect on strength, stiffness and deflection/rotation angle at yield and failure.

The results indicate that there is a reduction of strength and stiffness due to concrete shrinkage. The reduction of strength is $8-11 \%$ depending on the normalized axial load value. A significant reduction of the stiffness was observed. The reduction was considerably affected by the normalized axial load value. For large values of the normalized axial load the stiffness was considerably reduced when concrete shrinkage was simulated. A significant increment of deflection (or rotation angle) at yield and failure for high values of the normalized axial load can also be observed. 


\section{CONCLUSIONS}

The effect of restrained concrete shrinkage on the response of strengthened elements was investigated in this study. The results of an experimental investigation were presented and it was found that the compressive strength of the specimens is considerably reduced when there are tensile stresses due to restrained concrete shrinkage. Concrete shrinkage effect was also simulated using finite element method and jacketed columns were examined using different values of jacket's thickness and normalized axial load. Analyses were performed with and without the simulation of concrete shrinkage. Respective monolith columns were also examined and monolithic coefficient values were calculated. From the monolithic coefficient values the following conclusions can be drawn:

- The strength of the jacketed columns is reduced when the shrinkage of the jacket is simulated and the reduction was found to be in the range of $8-11 \%$ for all the examined specimens.

- The stiffness of the jacketed columns was also reduced and the reduction was higher as the normalized axial load was increased.

- The deflection/rotation angle of the columns at yield and failure was considerably increased. This increment was higher for the deflection/rotation angle at yield and for high values of the normalized axial load.

The effect of restrained concrete shrinkage is highlighted in this paper. It can be observed that restrained concrete shrinkage can reduce the concrete compressive strength and this can considerably reduce the strength and the stiffness of strengthened bridge pier columns. It is not conservative to neglect concrete shrinkage effect when strengthened elements with RC jackets are examined.

\section{REFERENCES}

[1] B.J. Bett, R.E. Klingner, J.O. Jirsa, Lateral load response of strengthened and repaired reinforced concrete columns, ACI Structural Journal 1988; 85(5), 499-508, 1988.

[2] U. Ersoy, A.T. Tankut, R. Suleiman, Behaviour of jacketed columns. ACI Structural Journal, 90(3), 288-293, 1993.

[3] M. Rodriguez, R. Park, Seismic load tests of reinforced concrete columns strengthened by jacketing, ACI Structural Journal, 91(2), 150-159, 1994.

[4] E.S. Julio, F. Branco, V.D. Silva, Structural rehabilitation of columns with reinforced concrete jacketing, Progress in Structural Engineering and Materials Journal, 5, 29-37, 2003.

[5] K.G. Vandoros, S.E. Dritsos, Interface treatment in shotcrete jacketing of reinforced concrete columns to improve seismic performance, Structural Engineering and Mechanics Journal, 23, 43-61, 2006.

[6] K.G. Vandoros, S.E. Dritsos, Concrete jacket construction detail effectiveness when strengthening RC columns. Construction and Building Materials Journal, 22(3), 264276, 2008.

[7] S. Bousias, D. Biskinis, M. Fardis, A.L. Spathis, Strength, stiffness and cyclic deformation capacity of concrete jacketed members, ACI Structural Journal, 104(5), 521-531, 2007. 
[8] A.P. Lampropoulos, O.T. Tsioulou, S.E. Dritsos, Biaxial Stress due to Shrinkage in Concrete Jackets of Strengthened Columns, ACI Materials Journal, 109(3), 331-340, 2012.

[9] A.P. Lampropoulos, S.E. Dritsos, Modelling of RC columns strengthened with RC jackets, Journal of Earthquake Engineering and Structural Dynamics, 40(15), 16891705, 2011.

[10] ACI 209R-92, Prediction of Creep, Shrinkage and Temperature Effects in Concrete Structures, American Concrete Institute, Farmington Hills, 1997.

[11] H. Kupfer, H. Hilsdorf, H. Rusch, Behavior of Concrete under Biaxial Stresses, American Concrete Institute Journal, 66(8), 656-666, 1969.

[12] V. Cervenka, L. Jendele, J. Cervenka, ATENA Program Documentation 2005, Cervenka Consulting, Prague, 2005.

[13] A.P. Lampropoulos, O.T. Tsioulou, S.E. Dritsos, Monolithic Coefficient Values for Design when Seismically Strengthening RC Columns with Jackets, Journal of Earthquake Engineering, 16(7), 1023-1042, 2012.

[14] A.P. Lampropoulos, S.E. Dritsos, Concrete Shrinkage Effect on Columns Strengthened With Concrete Jackets, Structural Engineering International, 20(3), 234-239, 2010.

[15] ATC 40, Seismic Evaluation and Retrofit of Concrete Buildings, Applied Technology Council, California, Vol. 1, 1996. 